\title{
Network Centrality Analysis of Public Transport Systems: Developing a Strategic Planning Tool to Assess Passenger Attraction
}

\author{
Amila Jayasinghe, Rattanaporn Kasemsri, C. Chethika Abenayake, P.K.S. Mahanama
}

\begin{abstract}
The objective of this study was to explore the potential of 'Network Centrality Analysis' method to estimate passenger attraction to public transportation (PT) stations. Accordingly, the study employed closeness centrality to measure the level of accessibility to a station from surrounding areas via a set of road segments; and betweenness centrality to measure the level of movement opportunities from a station to all other stations within the PT network. The result indicated that the network centrality is a useful indicator for estimating passenger volume at stations. The recorded $R^{2}$ values are on par with international standards. Further, the findings emphasized the ability of network centrality to account for passengers' attraction to stations in terms of accessibility to stations and movement opportunities. This method is highly recommended for assignments conducted in developing countries due to the less data consuming and technically simple nature
\end{abstract}

Index Terms: Centrality; Public Transport; Method; Network Analysis; Developing Countries; GIS

\section{INTRODUCTION}

Rapid economic growth in cities in developing countries accelerated increase of vehicular movements in urban areas. This situation raises the immediate necessity of improvement of public transport (PT) system in cities and urban areas. Accordingly, many cities attempted to improve the public transportation system by introducing mass transportation systems. However, many cites in developing countries are still struggling to make public transportation systems more attractive [1]. In developing public transportation system, identification of passenger attraction location and passenger movement are very important factors. However, many researches argue that lack of data and cost-effective modeling in developing counties constrained the development of effective strategies to improve public transportation. Accordingly, there is a urgent need to develop cost effective modeling methods model passenger attraction locations and movements [2], [3] [4]. This study attempts to develop an alternative method model passenger attraction to the public transportation stations. The method is develop based on network centrality analysis. The work of Hillier et al. on 'Space Syntax' has provided the initial development of the centrality analysis about road networks [5].

Revised Manuscript Received on July 20, 2019.

Dr. Amila Buddhika Jayasinghe, Senior Lecturer, Department of Town \& Country Planning, University of Moratuwa, Sri Lanka.

Dr. Rattanaporn Kasemsri, Lecturer, School of Civil Engineering, Suranaree University of Technology, Thailand.

Dr. C. Chethika Abenayake, Senior Lecturer, Department of Town \& Country Planning, University of Moratuwa, Sri Lanka.

Prof. P.K.S. Mahanama, Deputy Vice-Chancellor (DVC), University of Moratuwa. Sri Lanka.

Many recent study used space syntax to capture accessibility of location and explain the movement of people [5] [6] [7] [8]. However, limited attempts in the field of traffic and transportation to model passenger attraction to public transportation stations using spacy syntax or network centrality. Accordingly, this study try to explore the effectiveness of network centrality as a tool to model passenger attraction to public transportation stations.

The next section of the paper explicitly presents the previous work on the area of location of transit stops, passenger attraction and later about the principles of the network centrality concept. The third section discuss the method of study. Forth section brief the case study areas. Fourth section Fifth section discuss the results with reference to the application and the last section summarizes the work of this research with recommendations for policy makers and future research.

\section{LITERATURE REVIEW}

\section{A. Location of transit stops and Passenger Attraction}

Public transportation stations or stop is the first points of contact between the passenger and the public transportation system. Accordingly, location of transit stations or stop is an important factor affecting attraction of people to public transport systems. Research works of Murray \& Wu [11]; and Mohamed \& Foda [12] have found that public transportation users can be increased through locating public transportation station or stop in strategic location. Further, they have highlighted that importance of identification of those strategic location in the planning stage. So, it will help to attract more passengers to the public transportation systems. Sultana[13] emphasized the importance of connectivity between residential areas and central business district of cities as central factor for attracting more passenger to public transportation systems. Kain \& Liu [14], Ewing and Cervero [15] have indicated that residential and employment density, land use diversity and transport network connectivity are key factors in passenger attraction to public transportation systems. Kain \& Liu [14] and Cervero [16] argue that accessibility of the public transport station to downstream land use and upstream land use is most important factor in passenger attraction. Gomez-Ibanez [17] indicated that not only accessibility to land use but also service frequency, speed and service coverage are strongly associated with attraction of passengers towards public transport systems. 
Wang and Woo [18] found that employment density and availability of park ride facilities play key role in passenger attraction. Likewise, many researcher introduce many factors which are important to consider in passenger attraction in public transportation system. Accordingly, the study summarizes the some of key factors identified by literature in table I.

Table-I Factors effecting transit demand

\begin{tabular}{|c|c|c|c|c|c|c|c|c|c|c|c|c|c|}
\hline \multirow[t]{2}{*}{ Author } & \multicolumn{6}{|c|}{$\begin{array}{l}\text { Interaction between Land Use } \\
\text { and Transit Stop }\end{array}$} & \multicolumn{5}{|c|}{ Transit network configuration } & \multicolumn{2}{|c|}{$\begin{array}{l}\text { Facilities } \\
\text { available at } \\
\text { transit stop }\end{array}$} \\
\hline & 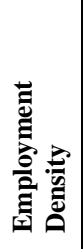 & 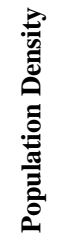 & 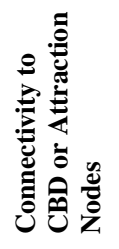 & 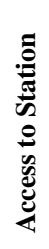 & 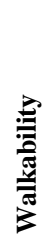 & 赵 & 苞 & 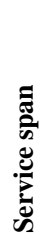 & 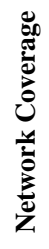 & 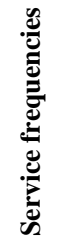 & 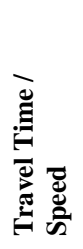 & 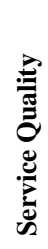 & 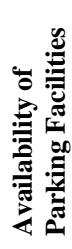 \\
\hline Pushkarev \& Zupan, 1977 & - & $\checkmark$ & - & - & - & - & - & - & - & - & - & - & - \\
\hline Hendrickson, 1986 & $\checkmark$ & $\checkmark$ & $\checkmark$ & - & - & - & - & - & - & - & - & - & - \\
\hline Liu, 1993 & $\checkmark$ & - & - & - & - & - & - & - & - & - & - & - & - \\
\hline Cervero, 1993 & $\checkmark$ & $\checkmark$ & - & $\checkmark$ & $\checkmark$ & $\checkmark$ & - & - & - & - & - & $\checkmark$ & $\checkmark$ \\
\hline Holtzclaw, 1994 & $\checkmark$ & $\checkmark$ & - & - & - & - & - & - & - & - & - & - & - \\
\hline Kain \& Liu, 1995 & $\checkmark$ & - & - & - & - & - & - & $\checkmark$ & $\checkmark$ & $\checkmark$ & $\checkmark$ & - & - \\
\hline Nelson \& Nygaard, 1995 & $\checkmark$ & $\checkmark$ & $\checkmark$ & - & - & - & $\checkmark$ & - & - & - & - & - & - \\
\hline Abdel-Aty \& Jovanis, 1995 & $\checkmark$ & $\checkmark$ & - & - & - & - & - & - & - & - & - & $\checkmark$ & $\checkmark$ \\
\hline Gomez-Ibanez, 1996 & $\checkmark$ & $\checkmark$ & $\checkmark$ & - & - & - & $\checkmark$ & $\checkmark$ & $\checkmark$ & $\checkmark$ & $\checkmark$ & - & - \\
\hline TCRP, 1996 & $\checkmark$ & $\checkmark$ & $\checkmark$ & - & - & - & $\checkmark$ & $\checkmark$ & $\checkmark$ & $\checkmark$ & $\checkmark$ & $\checkmark$ & $\checkmark$ \\
\hline Rosenbloom \& Clifton, 1996 & $\checkmark$ & $\checkmark$ & $\checkmark$ & - & - & - & - & - & - & - & - & - & - \\
\hline Handy, 1996 & $\checkmark$ & $\checkmark$ & - & $\checkmark$ & - & - & $\checkmark$ & - & - & - & - & - & - \\
\hline Chung, 1997 & $\checkmark$ & $\checkmark$ & - & - & - & - & $\checkmark$ & - & - & - & - & - & - \\
\hline Bernick \& Cervero, 1997 & - & - & - & - & $\checkmark$ & - & - & - & - & - & - & - & - \\
\hline Spillar \& Rutherfod, 1998 & $\checkmark$ & $\checkmark$ & - & - & - & - & $\checkmark$ & - & - & - & - & - & - \\
\hline Carane, 2000 & $\checkmark$ & $\checkmark$ & - & - & - & - & $\checkmark$ & - & - & - & - & - & - \\
\hline Kohna, 2000 & $\checkmark$ & $\checkmark$ & - & & - & - & $\checkmark$ & $\checkmark$ & $\checkmark$ & $\checkmark$ & $\checkmark$ & & \\
\hline Syed \& Khan, 2000 & $\checkmark$ & $\checkmark$ & - & - & - & - & - & - & - & - & - & $\checkmark$ & $\checkmark$ \\
\hline Mee, 2000 & - & - & - & - & - & $\checkmark$ & - & - & - & - & - & - & - \\
\hline Ewing et al., 2002 & $\checkmark$ & $\checkmark$ & - & $\checkmark$ & - & - & $\checkmark$ & - & - & - & - & - & - \\
\hline Chu, 2004 & $\checkmark$ & $\checkmark$ & $\checkmark$ & $\checkmark$ & - & - & $\checkmark$ & & - & - & - & - & - \\
\hline Dittmar \& Ohland, 2004 & - & - & - & - & $\checkmark$ & - & - & - & - & - & - & - & - \\
\hline Chiaradia, 2005 & - & - & $\checkmark$ & $\checkmark$ & - & - & $\checkmark$ & - & - & - & - & - & - \\
\hline Vuchic, 2005 & - & - & - & - & $\checkmark$ & - & - & - & - & - & - & - & - \\
\hline Leck, 2006 & $\checkmark$ & $\checkmark$ & - & - & - & - & - & - & - & - & - & - & - \\
\hline Foda \& Osman, 2008 & - & $\checkmark$ & - & $\checkmark$ & - & - & - & - & - & - & - & - & - \\
\hline Paul, 2009 & - & - & - & $\checkmark$ & - & - & - & - & - & - & - & - & - \\
\hline Winter, 2009 & - & - & - & - & - & - & $\checkmark$ & - & - & - & - & - & - \\
\hline Scheurer, 2010 & - & - & - & $\checkmark$ & - & - & $\checkmark$ & - & - & - & - & - & - \\
\hline
\end{tabular}

Note: ' $\checkmark$ ' Indicate the factors highlighted by respective authors

\section{B. Network Centrality Analysis}

Network centality analysis is method develop based on 'Graph Theory'. Erdos and Renyi [11] introdcued the 'Graph Theory'. Network centrality concepts were initially used in computer and social netowrk analysis. Recently, resercher utiliazed network centality to messure accessibility in spatial [2], [12]. Hiller [13] introduced the concept of 'centrality as a process' which enable to idenfily the human movement in meassure centality. urban strees. Centality of netowrk can be mssured by utlizing a set of centality paparmets. Closeness centrality and Betweenness centrality are commonly used paperments to

\section{Published By:}


Closeness Centrality (CC) measures how close the given nodes to all others nodes along the shortest path [15]. Closeness Centrality of nodes can be compute by using fomular intorduced by the Sabidussi's [16] (refer Eq.1.).

$C C_{i}=\frac{(N-1)}{\sum_{j \in N_{j} j \neq i} d_{i j}}$

Where,

$C C_{\mathrm{i}} \quad=$ Closeness centrality of node ' $\mathrm{i}$ '

$\mathrm{N}=$ Total number of nodes in a network

$d_{i j}=$ Distance between node ' $i$ ' and ' $\mathrm{j}$ ' along the shortest path

Betweenness Centrality (BC) is referred to the extent a given node belongs to the shortest-path between any pairs of two nodes in a network [15]. BC of nodes can be compute by using fomular intorduced by the Freeman's [14] (refer Eq.2.).

$$
B C_{i}=\frac{1}{(N-1)(N-2)} \sum_{j k \in N_{i} \neq k_{i} k \neq i} \frac{p_{j k_{(\mathbb{1})}}}{p_{j k}}
$$

Where,

$B C_{i} \quad=$ Betweenness centrality of node ' $\mathrm{i}$ '

$\mathrm{N}=$ Total number of node in a network

$p_{j k} \quad=$ Number of geodesics between node ' $\mathrm{j}$ ' and ' $\mathrm{k}$ '

$p_{j k_{(\mathbb{L})}}=$ Number of geodesics between node ' $\mathrm{j}$ ' and ' $\mathrm{k}$ ' that passing through node ' $i$ '

\section{METHOD OF STUDY}

According to the literature review findings related to passenger attraction towards public transport systems, the study concertized accessibility to origin the station / stop from surrounding land uses, travel time between origin and destination station / stop and accessibility to destination land uses from destination station / stop are key factors for passenger attraction public transport station / stop. Refer Fig. 1 for conceptual diagram.

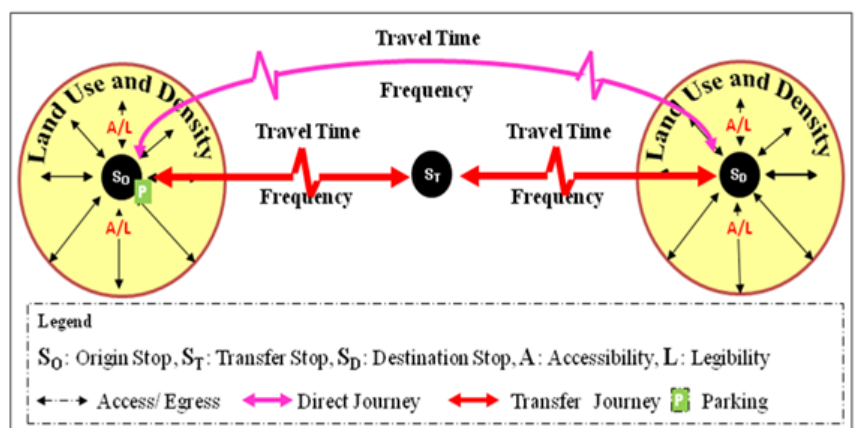

Figure 1- Conceptual diagrammatic outline of transit user decision making for selecting transit stops

Accordingly, the study has conceptualised the level of passenger attraction to a transit station as depending on two key factors as 1.) accessibility to the public transportation station/stop from origin/destination point (residential or employment area) of the trip maker, and 2.) movement opportunities from the public transportation station/stop across the public transportation stops. The study employed closeness centrality (CC) to capture $1^{\text {st }}$ factor and betweenness centrality (BC) to $2^{\text {nd }}$ factor. Accordingly, the study developed two centrality indices as Accessibility(A) and Movement opportunities(M). Table II summarises the key features of Accessibility(A) and Movement opportunities(M) indices.

The study developed two types of graph to compute BC and CC. Frist graph used to compute BC and it represents railway stations and road intersection as node and connection between them as links; and links, were weighted by physical distance. This graph uses to capture centrality of stations in terms of topological (unite) distance. Other graph is modified version of the first and use to capture centrality of station in terms of travel time. In this graph links were weighted by average travel time and service frequency. The study used all major roads and railway network which were extracted from secondary spatial data sources. The study employed 'spatial Design Network Analysis (sDNA)' tool in QGIS environment to compute $\mathrm{BC}$ and $\mathrm{CC}$.

Table-II Key features of the proposed centrality indices

\begin{tabular}{|l|l|l|}
\hline \multicolumn{1}{|c|}{ Index } & \multicolumn{1}{|c|}{ Accessibility(A) } & \multicolumn{1}{c|}{$\begin{array}{c}\text { Movement } \\
\text { opportunities(M) }\end{array}$} \\
\hline $\begin{array}{l}\text { Centrality } \\
\text { measure }\end{array}$ & $\begin{array}{l}\text { CC (Scheurer, Curtis and Porta } \\
\text { 2007) }\end{array}$ & $\begin{array}{l}\text { BC (Scheurer, Curtis } \\
\text { and Porta 2007) }\end{array}$ \\
\hline Network & Road network & PT network \\
\hline Node & Station/Road intersection & Station \\
\hline Link & Road segment & Transit line \\
\hline $\begin{array}{l}\text { Link } \\
\text { weighted }\end{array}$ & $1 /$ Topological distance & $\begin{array}{l}\text { Frequency of transit } \\
\text { service/Average travel } \\
\text { time }\end{array}$ \\
\hline Impact radii & $\begin{array}{l}\mathrm{R}=0.5 \mathrm{~km}, 1.5 \mathrm{~km}, 2.5 \mathrm{~km}, 5 \mathrm{~km}, \\
7.5 \mathrm{~km}, 10 \mathrm{~km}, 15 \mathrm{~km}\end{array}$ & R=r (Whole network) \\
\hline
\end{tabular}

\section{CASE STUDY AREAS}

The case studies were performed in Ahmedabad Municipal Council Area (AMC), India and Sri Lanka. In Ahmedabad study, the study look at the Bus network and Bus Rapid Transits system (BRTs) and Sri Lankan case study Railway network is considered. Ahmedabad is the fast growing city in India and considered as a commercial capital of Gujarat province. Further it is seven largest urban agglomeration in India with population of 5.7 million (2010) within the municipal area (466sqkm). Ahmedabad Municipal Transport System (AMTS) \& Janmarg Bus Rapid Transit System (BRTS) are the key agencies providing city public transport service. AMTS is the oldest system and it has network length of $549 \mathrm{Km}$ bus system. Janmarg Bus Rapid Transit System (BRTS) which is introduce in 2010 operates in $25 \mathrm{Km}$ route length (2010 July). Railway system of Sri Lanka has comprised with the 4 railway lines $(1449 \mathrm{Km})$ and 336 railway stations. 300 passenger trains are operating daily and it carry 290,000 passengers per day. 


\section{RESULT}

The analysis was carried at two different levels.

I. Graphic analysis

II. Spatial statistical analysis

Those analysis were employed to find out the nature and the strength of relationship between two indices and passenger attraction. Table III summarises the correlation results. Figure 2 illustrates the distribution of passenger volume and centrality values spatially. The overall correlation values for $\mathrm{CC}$ and $\mathrm{BC}$ are found higher correlation (>0.7) at BRTs in AMC. This means the stopsof the BRT are i. have high accessibility level to the transit station from origin/destination land use areas and ii. Provide high movement opportunities from the public transportation system. It is also important to state that BRT is Ahmedabad is a system which is entirely planned recently. In contrast the correlation between $\mathrm{CC}$ and passenger attraction for Bus $\mathrm{AMC}$ recorded in the moderate range while it is indicating a higher correlation with the BC. This indicates that nodes (bus stops) provide high movement opportunities from the transit station across the PT network. Higher BC depict, that passengers have better transit opportunities in the system.

In case of Sri Lankan Railways, the closeness centrality at a radius of $5 \mathrm{~km}$ show a relatively weak correlation compared to $7.5 \mathrm{~km}$ and $2.5 \mathrm{~km}$ radiuses. The correlation value for between centrality for Railway shows a moderate-positive relationship with a value of 0.62 correlation, which indicate that the system encourages moderate transit opportunities.

Table-III Summary of the correlation coefficient (r) values

\begin{tabular}{|c|c|c|}
\hline \multirow[t]{2}{*}{ PT network } & \multicolumn{2}{|c|}{ Centrality } \\
\hline & $\mathbf{C C}$ & BC \\
\hline \multirow{3}{*}{$\begin{array}{l}\text { Bus-AMC } \\
(\mathrm{n}=1398)\end{array}$} & $0.61 * *(\mathrm{R}=1.5 \mathrm{~km})$ & \multirow{3}{*}{$0.92 * *(\mathrm{R}=\mathrm{r})$} \\
\hline & $0.41 * *(\mathrm{R}=2.5 \mathrm{~km})$ & \\
\hline & $0.27 * *(\mathrm{R}=5 \mathrm{~km})$ & \\
\hline \multirow{3}{*}{$\begin{array}{l}\text { BRTs-AMC } \\
(\mathrm{n}=38)\end{array}$} & $0.73 * *(\mathrm{R}=5 \mathrm{~km})$ & \multirow{3}{*}{$0.81 * *(\mathrm{R}=\mathrm{r})$} \\
\hline & $0.71 * *(\mathrm{R}=1.5 \mathrm{~km})$ & \\
\hline & $0.68^{* *}(\mathrm{R}=2.5 \mathrm{~km})$ & \\
\hline \multirow{3}{*}{$\begin{array}{l}\text { Railway-SL } \\
(\mathrm{n}=130)\end{array}$} & $0.79 * *(\mathrm{R}=5 \mathrm{~km})$ & \multirow{3}{*}{$0.62 * *(\mathrm{R}=\mathrm{r})$} \\
\hline & $0.56^{* *}(\mathrm{R}=7.5 \mathrm{~km})$ & \\
\hline & $0.34 * *(\mathrm{R}=2.5 \mathrm{~km})$ & \\
\hline
\end{tabular}

Linear regression analysis was performed to investigate the relationship of passenger volume with the centrality values. Regression results indicated that passenger volume at a given station can be estimated by centrality values (Table. IV). The study utilized R-Squared-R ${ }^{2}$ (refer Eq. 3) to assess the goodness-of-fit when selecting the most suitable model. R-Squared provide better judgment about the predictability of the model.

$R^{2}=1-\frac{\sum\left(y_{n}-y_{n}\right)^{2}}{\sum\left(y_{n}-\not\right)^{2}}$

where;

$R^{2}=$ Coefficient of determination

$y_{n}=$ actual value

$\bar{y} \quad=$ mean of actual value

Table-IV Summary of regression analysis

\begin{tabular}{|c|c|c|c|c|c|c|c|c|}
\hline \multirow{2}{*}{$\begin{array}{c}\text { PT } \\
\text { network }\end{array}$} & \multirow{2}{*}{\begin{tabular}{|l|} 
R-Squ \\
ared
\end{tabular}} & \multirow{2}{*}{ Variables } & \multirow[t]{2}{*}{ Beta } & \multirow[t]{2}{*}{ Sig. } & \multicolumn{3}{|c|}{ Correlations } & \multirow[t]{2}{*}{ VIF } \\
\hline & & & & & $\begin{array}{l}\text { Zero- } \\
\text { order }\end{array}$ & $\begin{array}{l}\text { Par } \\
\text { tial }\end{array}$ & Part & \\
\hline \multirow[t]{3}{*}{ Bus-AMC } & \multirow[t]{3}{*}{0.928} & Constant & & .000 & & & & \\
\hline & & BC_r & .618 & .000 & .92 & .79 & .39 & 2.45 \\
\hline & & CC_2.5km & .424 & .000 & .61 & .52 & .27 & 2.45 \\
\hline \multirow{3}{*}{$\begin{array}{c}\text { BRTs-A } \\
\text { MC }\end{array}$} & \multirow[t]{3}{*}{0.871} & \begin{tabular}{|l|} 
Constant \\
\end{tabular} & & .000 & & & & \\
\hline & & BC_r & .615 & .000 & .81 & .74 & .54 & 1.28 \\
\hline & & CC_5 km & .393 & .000 & .73 & .57 & .34 & 1.28 \\
\hline \multirow{3}{*}{$\begin{array}{c}\text { Railway-S } \\
\text { L }\end{array}$} & \multirow{3}{*}{0.814} & Constant & & .000 & & & & \\
\hline & & CC_5km & .639 & .000 & .79 & .73 & .57 & 1.25 \\
\hline & & BC_r & .335 & .000 & .62 & .49 & .29 & 1.25 \\
\hline
\end{tabular}

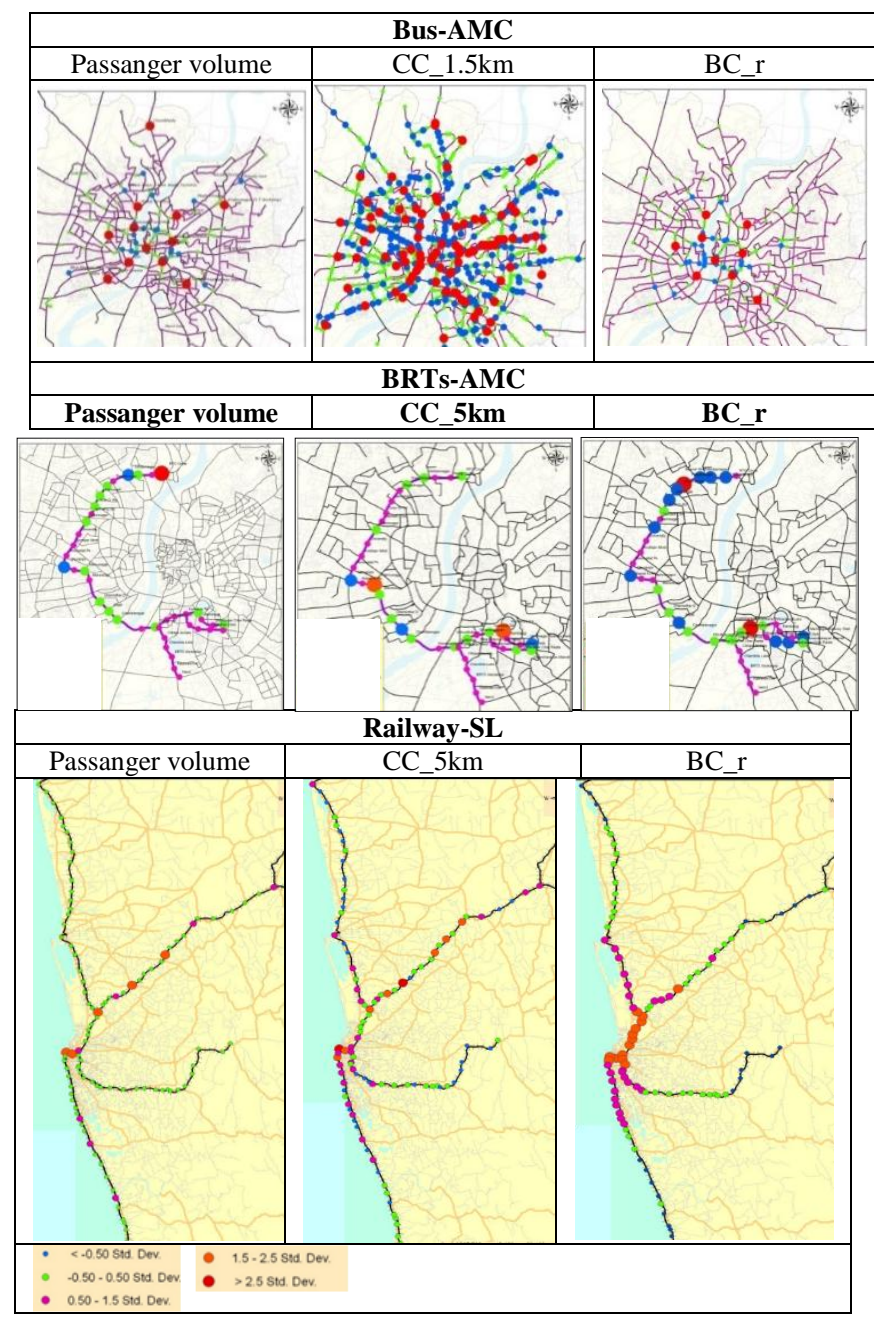

Fig. 2- Spatial distribution of passenger volumes and centrality values

Partial-correlation values indicated that movement opportunities from the transit station across the public transportation network (i.e. BC_r) revealed $79 \%$ influence while accessibility to the station from $2.5 \mathrm{Km}$ radius area (i.e. CC_2.5 Km) revealed 52\% influence over passenger attraction to bus stations.

Published By:

Blue Eyes Intelligence Engineering 
In BRTs stations, movement opportunities from the transit station across the public transportation network (i.e. BC_r) has recorded $74 \%$ and accessibility to the station from $\% \mathrm{Km}$ radius area ((i.e. CC_5 $\mathrm{KKm})$ has recorded $57 \%$ influence.

For railway stations in Sri Lanka, accessibility to the station from $5 \mathrm{Km}$ radius area (i.e. CC_\% $\mathrm{Km}$ ) has revealed $73 \%$ influence while opportunities from the transit station across the public transportation network (i.e. BC_r) has revealed $49 \%$ influence over passenger attraction to train stations. This is an indication that the stations are located at mode transit locations where passengers usually travel $5 \mathrm{Km}$ to use the train service.

\section{CONCLUSION AND RECOMMENDATION}

The objective of this study was to develop an alternative method model passenger attraction to the public transportation stations using 'Network Centrality Analysis' The findings of the study indicated that the network centrality analysis is a suitable method to model passenger volume at stations. The recorded $\mathrm{R}^{2}$ values are on par with international standards (i.e. Federal Highway Administration, United State of America; $\left.\mathrm{R}^{2}>0.85\right)$. Further, the findings emphasized the ability of network centrality to account for passengers' attraction to stations in terms of accessibility to stations and movement opportunities.

This method is highly recommended for assignments conducted in developing countries due to less data consuming nature and technically simple. Therefore, the method can be utilized as a strategic modeling tool in identifying strategic interventions to attract more passengers to public transportation system or to analyses the attractiveness of a proposed public transportation system.

\section{REFERENCES}

1. S. Ahmad and J. A. P. de Oliveira, "Determinants of urban mobility in India: Lessons for promoting sustainable and inclusive urban transportation in developing countries," Transport Policy, vol. 50, pp. 106-114, 2016

2. A. Jayasinghe, K. Sano, C. C. Abenayake and P. Mahanama, "A novel approach to model traffic on road segments of large-scale urban road networks," MethodsX, vol. 6, pp. 1147-1163, 2019.

3. A. Paul, "An integrated approach to modeling vehicular movement networks: Trip assignment and space syntax," 2009

4. K. Hamad and A. Faghri, "An Innovative Methodology for Vehicular Demand Forecasting in Developing Countries," in TRB Annual Meeting-2003, Washington DC, 2003.

5. J. Scheurer, C. Curtis and S. Porta, "Spatial Network Analysis of Public Transport Systems: Developing a Strategic Planning Tool to Assess the Congruence of Movement and Urban Structure in Australian Cities," Australasian Centre for the Governance and Management of Urban Transport, Perth, 2007.

6. A. Jayasinghe, K. Sano and K. Rattanaporn "Application for developing countries: Estimating trip attraction in urban zones based on centrality," Journal of Traffic and Transportation Engineering (English Edition), vol. 4, no. 5, pp. 464-476, 2017.

7. Z. Huang and X. Liu, "A hierarchical approach to optimizing bus stop distribution in large and fast developing cities," ISPRS International Journal of Geo-Information, vol. 3, no. 2, pp. 554-564, 2014.

8. S. Derrible, "Network Centrality of Metro Systems," PLOS ONE, vol. 7, no. 7, p. e40575, 2012.

9. A.T. Murray and X. Wu, "Accessibility tradeoffs in public transit planning," Journal of Geographical Systems, vol. 5, no. 1, pp. 93-107, 2003.

10.M. Foda and A. Osman, "Using GIS for measuring transit stop accessibility considering actual pedestrian road network," Journal of Public Transportation, vol. 13, no. 4, pp. 23-40, 2010.

11.S. Sultana, "Transportation and Land Use," The International Encyclopedia of Geography, vol. 6, no. 3, pp. 374-385, 2007.
12.J. Kain and Z. Liu, "Secrets of success: assessing the large increases in transit ridership achieved by Houston and San Diego transit providers,' Transportation Research Part A, vol. 33, p. 601-624, 1999.

13.R. Ewing and R. Cervero, "Travel and the built environment: a synthesis Transportation Research Record," Journal of the Transportation Research Board, vol. 1780, pp. 87-114, 2001.

14.R. Cervero, Ridership Impacts of Transit-focused Development in California, Berkeley: University of California Transportation Center, 1993.

15.G. Gomez-Ibanez, "Big-city transit, ridership, deficits, and politics," Journal of the American Planning Association, vol. 62, no. 1, pp. 30-50, 1996.

16.W. K. and M. Woo, "The relationship between transit rich neighborhoods and transit ridership: Evidence from the decentralization of povery," Applied Geography, vol. 86, no. 1, pp. 183-96, 2017.

\section{AUTHORS PROFILE}

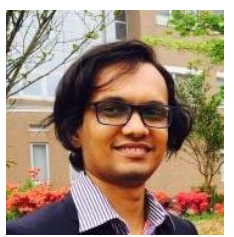

Dr. Amila Buddhika Jayasinghe is a senior lecturer at the Department of Town \& Country Planning, University of Moratuwa, Sri Lanka. His research works are focused on urban simulation, open source GIS applications, transport network analysis and public transportation in developing countries. Dr. Jayasinghe is a charted town planner.

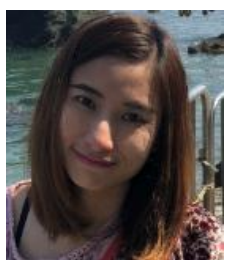

Dr. Rattanaporn Kasemsri is a lecturer at the School of Civil Engineering, Suranaree University of Technology, Thailand. Her research works are focused on optimization distribution network, traffic simulation, using Bluetooth technology to estimate traffic parameters. Dr. Kasemsri is a charted transportation planner.

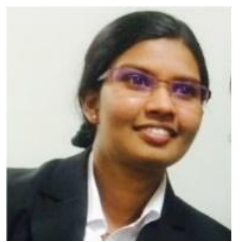

Dr. C. Chethika Abenayake is a senior lecturer at Department of Town \& Country Planning, University of Moratuwa, Sri Lanka Her research works are focused on environmental assessments, planning theory and methods. Dr. Abenayake is a charted town planner and a professionally qualified environmental planner.

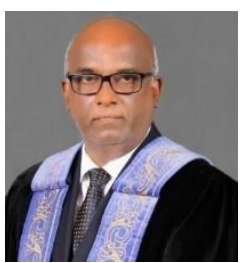

Prof. P.K.S. Mahanama currently works as a Deputy Vice-Chancellor (DVC), University of Moratuwa. Prof. Mahanama is a leading urban planner in Sri Lanka and his research works are focused on Urban and Regional Planning, Environment Planning, and GIS applications in Spatial Planning. 